\title{
A longitudinal study of gastrointestinal parasites in English dairy farms. Practices and factors associated with first lactation heifer exposure to Ostertagia ostertagi on pasture
}

\author{
C. Bellet, ${ }^{* 1,2}$ M. J. Green, ${ }^{*}$ A. J. Bradley, ${ }^{*} \dagger$ and J. Kaler* \\ ${ }^{*}$ School of Veterinary Medicine and Science, University of Nottingham, Sutton Bonington Campus, Sutton Bonington, Leicestershire, LE12 5RD, \\ United Kingdom \\ †Quality Milk Management Services Ltd. (QMMS), Cedar Barn, Easton Hill, Easton, Nr Wells, Somerset, BA5 1DU, United Kingdom
}

\begin{abstract}
The gastrointestinal nematode Ostertagia ostertagi is an important cause of lost production, health, and welfare in cattle. Detailed records were obtained over a 5 -yr period (2010-2015) by questionnaires and qualitative interviews to investigate the practices adopted by dairy farmers to control cattle helminth infections and the factors associated with heifer exposure to $O$. ostertagi on pasture. In total, 1,454 heifers' individual milk samples were collected over a 1-yr period (2014-2015) in 43 dairy farms in England and tested for O. ostertagi antibody by ELISA. Multilevel linear regression models were used to investigate the association between individual milk optical density ratio (ODR) against $O$. ostertagi and heifer management from birth to time of sampling. Farm and heifer median ODR against $O$. ostertagi were 0.98 (interquartile range $=0.76-1.02$ ) and 0.64 (interquartile range $=0.42-0.84$ ), respectively. The majority of heifers (88\%) received an anthelmintic treatment before sampling in this study. After controlling for the effect of anthelmintic treatments, heifer individual milk ODR against $O$. ostertagi significantly increased with high stocking rate at first grazing and co-grazing with adult cows before calving. Conversely, heifer individual milk ODR against $O$. ostertagi significantly decreased when heifers had co-grazed with sheep and pasture grass had frequently been mowed. Overall, these results provide evidence to support targeting grazing management toward limiting the use of anthelmintics in dairy young stock to enable sustainable control of cattle helminth infections in England. However, to be accepted and adopted by farmers, these
\end{abstract}

\footnotetext{
Received March 29, 2017.

Accepted September 14, 2017.

${ }^{1}$ Corresponding author: camille.bellet@liverpool.ac.uk

${ }^{2}$ Current address: Institute of Infection and Global Health, University of Liverpool, IC2 Building, 146 Brownlow Hill, Liverpool, L3 5RF, United Kingdom.
}

best practices would need to take into account farmers' perspectives and contextual challenges.

Key words: dairy heifer, Ostertagia ostertagi, individual milk ELISA, sustainable control

\section{INTRODUCTION}

Ostertagia ostertagi infections are one of the main concerns in the cattle industry in England (Bellet et al., 2016; Berk et al., 2016). Extensive negative effects of cattle helminths have been reported, including loss in milk production, decreased growth performances, impaired reproduction, and poor welfare (Sanchez et al., 2002a; Charlier et al., 2014; Bellet et al., 2016); moreover, cattle infected with helminths produce more greenhouse gases (Rushton and Bruce, 2017). As cattle helminth infections are mainly subclinical, their control is often difficult (Charlier et al., 2014) and mostly relies on the indiscriminate use of anthelmintic drugs (Vercruysse and Claerebout, 2001). In the United Kingdom (UK), concerns over cattle anthelmintic resistance have led to the development of the Control Of Worms Sustainably guidelines (COWS, 2010), but their adoption by cattle farmers in England is still unsatisfactory (Heasman et al., 2012). Whereas some information is available on the use of management practices by sheep farmers for helminth control in England (Morgan et al., 2012), scant data exists on the same for the dairy farmers.

To implement helminth control, farmers need to use basic epidemiological information (Vercruysse and Claerebout, 2001). This includes information on a wide range of factors on which exposure of cattle to helminths depends; for example, climate, farm management (e.g., stocking rate and mowing), and availability of resources (Charlier et al., 2015; Wilson et al., 2015). In dairy farms, this is particularly relevant to heifers, as these are the future of the milking herd and usually the focus of anthelmintic treatments (COWS, 2010; AHDB, 2015). However, estimations of dairy heifer 
exposure to helminths on pasture are currently unavailable in England. In fact, no survey on the prevalence of helminths in dairy heifers have been conducted in England since the 1980s (Hong et al., 1981). Moreover, although the identification of risk factors associated with cattle exposure to $O$. ostertagi has been the focus of much research, there is a lack of similar research focused on heifers. In addition, it remains unknown if and how these risk factors can interplay and vary over the lifetime of the cattle (Charlier et al., 2005a; Bennema et al., 2009; Vanderstichel et al., 2012). One possible reason for this is the use in previous research of closeended questionnaires, which restricts the representation of complex systems of management and grazing (Bennema et al., 2010; Merlin et al., 2016). This is especially the case when these approaches are applied to systems such as the ones adopted in England, where cattle graze in rotation (AHDB, 2013). Second, previous studies mainly relied on bulk tank milk (BTM) indicators of cattle exposure to helminths whose antibody levels are difficult to interpret because of the pooled nature of the samples (Sekiya et al., 2013). Evidence suggests that because levels of $O$. ostertagi antibody in cows are highly varied within a farm, the use of individual milk (IM) samples for this type of research is a better approach (Charlier et al., 2007; Blanco-Penedo et al., 2012).

The goal of our research was to provide a better understanding of strategies to improve the control of helminth infections in heifers in England. To achieve this, we used a longitudinal study (integrating both retrospective and prospective data on individual heifer management, from birth to first lactation) to explore (1) levels of herd and heifer exposure to helminths, (2) farmers' practices for cattle helminth control, and (3) factors associated with heifer exposure to O. ostertagi on pasture.

\section{MATERIALS AND METHODS}

\section{Study Herds}

Heifers came from a convenience and purposive sample of 43 dairy farms, all members of the Quality Milk Management Services (QMMS) recording scheme in Somerset, England. The average size of herds sampled was 150 cows, of which 46 were first-lactation heifers. Farms were selected to allow the representation of different levels of heifer exposure to helminths and heifer management. Farm selection criteria included heifers calving all-year-round or at least during 2 different seasons in a year, home rearing of heifers (i.e., not contract reared), compliance on data recording, agreeing with the study protocol, and sharing farm records.
Heifer IM samples were obtained from samples routinely collected and stored by QMMS. All heifers entering in first lactation from the beginning of March 2014 to the end of March 2015 were eligible for the study. A total of 1,500 heifer samples were selected by stratified random sampling, with the season and the farm as the strata (Dohoo et al., 2009). The selection of the samples was conducted in 2 steps (October 2014 and June 2015). We aimed to obtain 375 heifer samples per season and 35 per farm. A flowchart of the selection process of the samples is presented Figure 1. Inclusion criteria were DIM (i.e., between 30-90 DIM to limit the confounding effect of milk production factors on antibody levels; Sanchez et al., 2004), presence of QMMS sample records on milk yield, fat, protein, and SCC, and absence of heifer grazing in 2015. In the case where multiple samples had been collected from a heifer, only the sample with the lowest DIM was kept to be tested.

\section{Data Collection}

The study was approved by the ethics committee of the School of Veterinary Medicine and Science, University of Nottingham, and participating farmers were asked to sign an informed consent form. Detailed retrospective and prospective information on heifer's demographic and management was obtained for a 5 -yr period from 2010 to 2015. This way, each sampled heifer presented a complete management history from birth to sampling.

Postal Questionnaires (Retrospective Information on Heifer General Management). Retrospective information on demographic (i.e., farm and heifer) and general young stock management (i.e., housing, feeding, and vaccination) was gathered for each heifer and farm using close-ended questionnaires. Information was collected for the years 2010 to 2013, assuming that first-lactation heifers could calve from 30 mo onwards in Great Britain (AHDB, 2014). Questions were grouped into sections according to topics (e.g., demographic, housing, and vaccination) and animal category (e.g., preweaned calves, weaned calves, and bulling heifers). Questions were asked for the year 2013 and, in the case of any change from the previous years (i.e., 2010-2012), farmers were asked to specify this change. Before its distribution, the questionnaire was pilot-tested on 3 colleagues of the dairy herd health research group at the School of Veterinary Medicine and Science, University of Nottingham. Collected data were validated with farmers during a subsequent farm visit.

Farm Visit (Retrospective Information on Heifer Grazing Management). Forty-three face-toface semistructured interviews were conducted by the lead author (CB) during a farm visit between April and 
May 2014 to collect retrospective data on each heifer grazing management for the years 2011 to 2013. The interviews were audio-recorded and followed a pilottested interview schedule. Only managers with day-today responsibility for the dairy herd were interviewed. The interview schedule was divided into 3 different sections that referred to 3 different animal categories; that is, (1) calves (i.e., defined as animals from weaned to
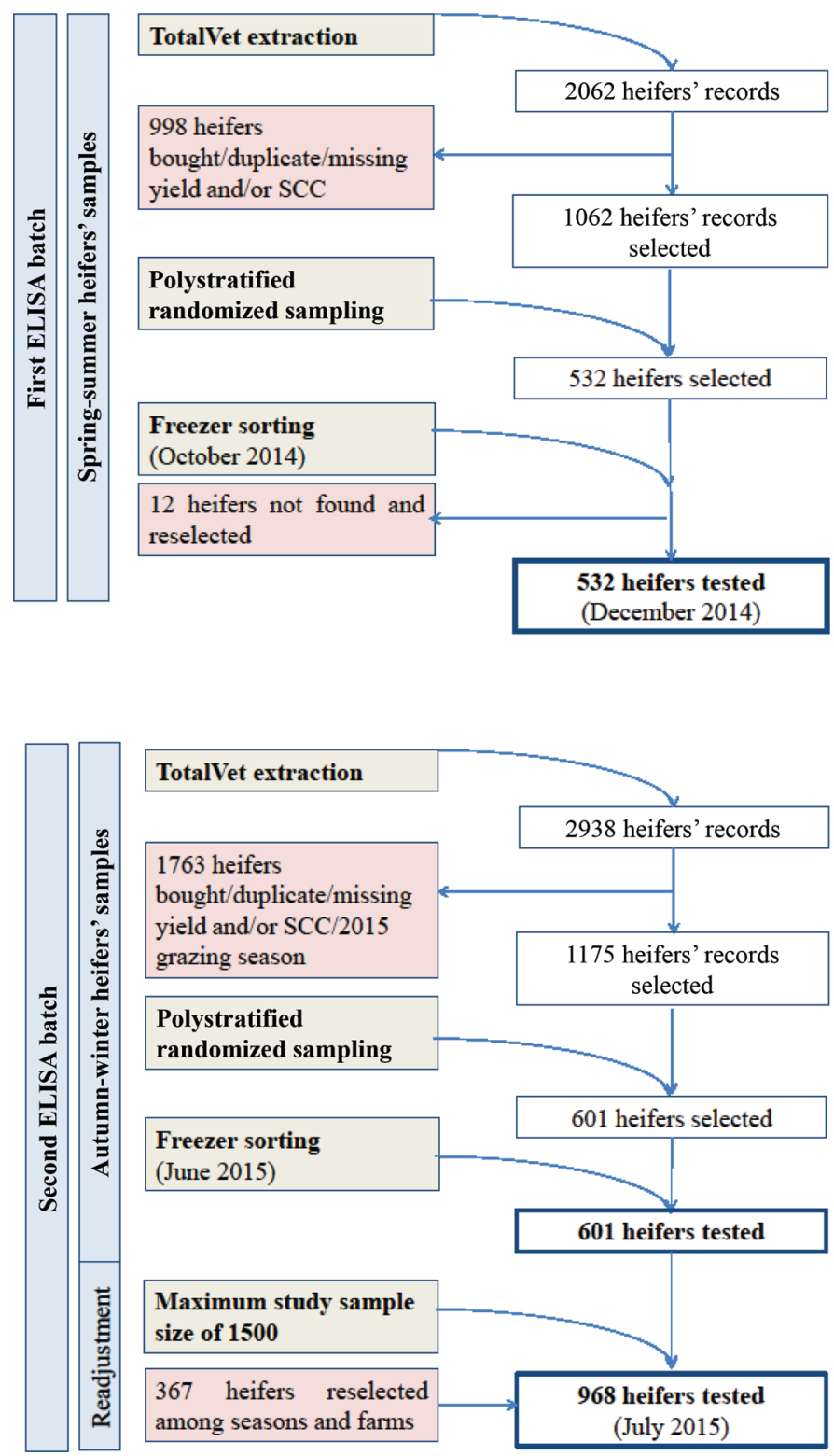

Figure 1. Illustration of the stratified random sampling used for the selection of the 1,500 heifer individual milk samples tested for Ostertagia ostertagi. Parameters of heifer's milk sample were extracted from QMMS information management system and processed using the dairy herd data analysis program, TotalVet (QMMS Ltd./Sum-It Computer Systems Ltd., Oxfordshire, UK). Color version available online. bulling age), (2) bulling heifers (i.e., defined as animals from bulling age to in-calf), and (3) in-calf heifers (i.e., defined as animals from in-calf to not-yet-calved). The definition of these terms was developed beforehand and discussed with farmers to avoid any misunderstanding. The questions referred to the period between 2011 and 2013 for calves and between 2012 and 2013 for bulling and in-calf heifers. For each year and category, questions were split into 3 time periods to facilitate the data collection: (1) from the time of animal turn-out to June 1; (2) from after June 1 to August 1; and (3) from after August 1 to the time of animal housing. Animal grazing seasons, defined by the interval between turn-out and housing, were confirmed by farmers for each year (i.e., 2011, 2012, and 2013). For each category and time period, questions were asked about numbers of heifer groups, ages of heifers within each group, movements of heifers between groups, and number of pastures grazed per group. For each pasture grazed, farmers were asked to provide details on time of entry and exit of heifers, size of pasture, previous grazing on pasture, co-grazing, mowing, fertilization, and individual anthelmintic treatments. Given the complexity of some of the rotational grazing management systems, information was checked against detailed maps of the farms' grazing fields.

Telephone Interviews (Prospective Information on Heifer General and Grazing Management). At the end of the farm visit, farmers were asked to record the same information for the on-going grazing season (i.e., 2014) and for their upcoming housing management (i.e., 2014-2015). These data were collected once every 3 mo by telephone until March 2015 .

QMMS Information Management System. Parameters of heifer's milk sample (i.e., date of sampling, date of first calving, breed, DIM, milk yield and SCC) were extracted from the QMMS information management system and processed using the dairy herd data analysis program, TotalVet (QMMS Ltd./Sum-It Computer Systems Ltd., Oxfordshire, UK).

\section{Laboratory Procedures}

Pilot Study. A pilot study was conducted to evaluate the effect of milk samples storage on ELISA results. Eighty-six IM samples from adult cows that had been tested for $O$. ostertagi in 2012 and then stored at $-20^{\circ} \mathrm{C}$ were tested again under similar laboratory conditions in March 2014. The test used the same ELISA kit and followed manufacturer's instructions (Svanovir, Uppsala, Sweden, http://www.svanova.com/products/bovine/ bp15.html). Results were adjusted using a QMMS internal control before they were compared. Agreement of paired test results was computed using Lin's concordance correlation coefficient (Lin, 1989). 
ELISA Milk Testing. After collection on farms, composite IM samples were preserved using bronopol/ natamycin and kept at ambient temperature until arrival at the laboratory. In the laboratory, the samples were processed and tested for SCC, fat, and protein before being frozen at $-20^{\circ} \mathrm{C}\left( \pm 2^{\circ} \mathrm{C}\right)$ until further testing; this was achieved within the first $48 \mathrm{~h}$ after sample collection on farms. Only IM samples from heifers born after 2010 and having grazed before sampling were tested for $O$. ostertagi. To limit cross-reactivity between the crude antigen used for $O$. ostertagi ELISA testing and Fasciola hepatica antibodies (Bennema et al., 2009), herd-level exposure to F. hepatica was determined by antibody-detection ELISA applied on BTM at the end of the grazing season 2014, in each farm (i.e., from October to December 2014). The BTM samples were also tested for O. ostertagi; IM and BTM samples were defrosted, defatted by centrifugation $(2,000 \times$ $g, 20^{\circ} \mathrm{C}, 2 \mathrm{~min}$ ), and their supernatant was collected. Samples were tested undiluted without any duplicate sampling and ELISA tests were carried out according to kits manufacturer's instructions. The ELISA tests were conducted by the same technician, blinded to the identity of the animal. The F. hepatica test used the Pourquier ELISA $F$. hepatica serum and milk verification test (Idexx, Montpellier, France), which is based on an f2 antigen purified from $F$. hepatica extracts. Results were expressed as a percent positivity (PP), after assessment of the corrected optical density of the sample at $450 \mathrm{~nm}$ and calculation of the percentage of the positive control. The O. ostertagi test used the Svanovir kit sourced from Svanova Ltd. (Uppsala, Sweden), which is an indirect ELISA based on crude saline extracts of $O$. ostertagi adult worm as antigens (Keus et al., 1981; Sanchez et al., 2002c). Results were expressed as an optical density ratio (ODR) of the sample to guarantee test repeatability (Sanchez et al., 2002c), after the measure the optical density of both sample and positive and negative controls at $405 \mathrm{~nm}$.

\section{Data Collation and Statistical Analysis}

Computer data entry was conducted using Microsoft Excel and Access (version 2013, Microsoft Corp., Redmond, WA). Due to the nature and the complexity of the grazing management information, a systematic process of data entry was performed for each heifer included in this study. First, farm housing system and heifer's date of birth estimated the year, the month, and the age of the heifer at first turn-out, each heifer was then affiliated to a category and a group within that category for the first grazing season, and, finally, this was used to infer on heifer-specific grazing management until housing for the first grazing season. Taking the previous grazing season as a reference, we could then estimate the age of heifer for the next grazing season and repeat the same process for each grazing season until a heifer was sampled. If heifers were born before 2010 or were never turned out, they were excluded from the study. Iterative and triangulation processes (Dohoo et al., 2009) between the different data sources (i.e., questionnaire, interviews, and QMMS information management system) were used to enhance the quality of the final grazing management database.

Data were collated and initially analyzed using Stata 12.1 (Stata Inc., College Station, TX). As farmers did not report significant changes in their farming after 2010, a general profile of demographic and management practices (except grazing) was established for each farm. Descriptive and graphical analyses (e.g., scatterplot) were carried out to explore farm's and heifer's data. Pearson correlation coefficient (McDonald, 2014) was calculated between BTM and heifer IM ODR, considering all heifer samples in a given farm for the defined period of BTM sampling (i.e., October-December 2014). Related correlations interpreted as strong (above \pm 0.60 ), moderate (between \pm 0.40 and \pm 0.59 ) or weak (below $\pm 0.39 ;$ McDonald, 2014). A $P$-value $\leq 0.05$ was considered significant.

A multilevel linear regression (random effects) model (Dohoo et al., 2009) was used to investigate the association between heifer IM ODR and collected and constructed variables on cow, farm, and heifer management. Constructed variables consisted in providing the time sequence of heifer exposure to the factor of interest from birth to time of sampling (e.g., heifer treatment protocol and co-grazing with adult cows). The model incorporated 2 hierarchical levels, given that several heifers originated from the same farm: level $1(i)$, the heifer level, and level $2(j)$, the farm level. The outcome variable was heifer IM ODR. All collected variables were first tested in a univariable multilevel linear regression model. The model was developed using a reweighted generalized iterative least squares algorithm in MLwiN 2.30 (Rasbash et al., 2012) and took the form

$$
y_{i j}=\boldsymbol{\beta}_{0}+\boldsymbol{\beta}_{1} \mathbf{x}_{i j}+\boldsymbol{\beta}_{2} \mathbf{x}_{j}+v_{0 j}+e_{i j},
$$

where subscripts $i$ and $j$ denote the $i$ th heifer of the $j$ th farm, respectively; $y_{i j}=$ heifer IM ODR; $\boldsymbol{\beta}_{0}=$ intercept value; $\boldsymbol{\beta}_{1}=$ vector of coefficients for $\mathbf{x}_{i j} ; \mathbf{x}_{i j}=$ vector of covariates associated with each heifer; $\boldsymbol{\beta}_{2}=$ vector of coefficients for $\mathbf{x}_{j} ; \mathbf{x}_{j}=$ vector of covariates associated with each farm; and $v_{0 j}$ and $e_{i j}$ were random effects to account for residual variation between farms and heifers, respectively, both assumed to be normally distributed. Associations between heifer IM ODR and collected variables were evaluated using a stepwise 
approach with elimination of nonsignificant effects $(P$ $>0.05$ ) and observation of overall significance of factors. Based on Wald tests, all significant main effects at $P \leq 0.05$ were left in the model. Information on known confounding variables, as identified from previous literature (Klesius, 1993; Kloosterman et al., 1993; Sanchez et al., 2004), was collected and these variables were retained in the final model; confounding variables included were herd size, BTM ODR, BTM PP, breed, record season, DIM, milk yield, and $\log (\mathrm{SCC})$. We explored interactions among predictors that were found to be significant in main effects model. This was done in 2 ways: descriptive plots of the variables with outcome, and including statistical 2-way interactions between predictors, and checking the significance of the main effects and the interaction term (Dohoo et al., 2009). Model goodness-of-fit was assessed by examination of QQ plots and kurtosis of residual distributions (Dohoo et al., 2009). Collinearity was explored by calculating the variance inflation factor of the variables included in the model (Dohoo et al., 2009; Rasbash et al., 2012).

\section{RESULTS}

\section{Pilot Study}

The concordance correlation coefficient with $95 \%$ confidence interval between the 2012 and 2014 mean ODR of cow IM samples were substantial and ranged from 0.87 (0.82-0.92; no ODR adjustment) to 0.89 (0.84-0.93; ODR adjustment).

\section{Study Population}

Of the 43 dairy farmers included in the study, 2 withdrew shortly after the farm visit, resulting in a study participation rate of $95 \%$. Main characteristics of the 41 farm participants are presented Table 1. Most of the farms (80\%) were clustered around southwest counties, including counties of Somerset $(\mathrm{n}=18)$, Wiltshire $(\mathrm{n}=9)$, Devon $(\mathrm{n}=3)$, Cornwall $(\mathrm{n}=2)$, and Gloucestershire $(\mathrm{n}=1)$. A total of 1,454 heifer IM samples were included in the analysis, with 350 collected in spring (i.e., between April and June), 357 in summer (i.e., between July and September), 373 in autumn (i.e., between October and December), and 375 in winter (i.e., January and March). The median number [interquartile range (IQR), 25-75\%] of heifers sampled per farm was 34 (25-44). Sampled heifers were predominantly Holstein Friesian, with $83 \%$ purebreds $(\mathrm{n}=1,207)$ and $8 \%$ crossbreds $(\mathrm{n}=117)$. Most heifers were born in $2012(\mathrm{n}=1,013 ; 70 \%)$ and $2011(\mathrm{n}=384$; $26 \%)$; the rest were born in $2013(\mathrm{n}=45 ; 3 \%)$ and 2010 $(\mathrm{n}=12 ; 1 \%)$. The median ages (IQR) of heifers at first turn-out and first calving were $9.5(6.9-13.6)$ and 27.3 (25.0-30.6) mo, respectively. Most heifers (59\%) had 2 grazing seasons before sampling, others had $1(17 \%)$ or more than 2 (24\%). In total, 85 and $44 \%$ of the farmers systematically dewormed their young stock and adult cows, respectively. Out of the sampled heifers, $88 \%$ from 39 farms (95\%) had received at least 1 anthelmintic treatment before sampling. Farmers predominantly used pour-on ( $\mathrm{n}=27 ; 77 \%)$ and long-acting forms of anthelmintics $(\mathrm{n}=23 ; 66 \%)$ in young stock. The most common anthelmintic class used in young stock was macrocyclic lactones (ML; $\mathrm{n}=31 ; 89 \%$ ), in particular ivermectin compound $(\mathrm{n}=23 ; 66 \%)$. Around half of the farms $(\mathrm{n}=17)$ exclusively relied on 1 anthelmintic compound to treat their young stock against parasites. Moreover, 37, 29, and 5\% of the farmers treated their heifers more than 3 times in a given grazing season before sampling (treatment range: season $1=4-10$; season $2=4-5$; and season $3=5-5$ ).

\section{Farm and Heifer Exposure to Ostertagia ostertagi and Fasciola hepatica}

The median (IQR) PP and ODR estimated in BTM at the end of the grazing season 2014 in the study farms were $20.30(4.38-89.33)$ and $0.98(0.76-1.02)$, re-

Table 1. Characteristics of the 41 farms included in the dairy longitudinal study

\begin{tabular}{lrc}
\hline Variable & No. & $\%$ \\
\hline Enterprise & 35 & 85 \\
$\quad$ Conventional (including integrated) & 6 & 15 \\
$\quad$ Organic & 24 & 59 \\
Production & 17 & 41 \\
$\quad$ Pure-dairy & & \\
$\quad$ Mixed (including beef or sheep) & 26 & 63 \\
Closed herd & 15 & 37 \\
$\quad$ No & & \\
Yes & 16 & 39 \\
Total dairy staff & 25 & 61 \\
$\quad<5$ & & \\
5-22 & 9 & 22 \\
Number of adult dairy cows & 12 & 29 \\
$\quad<100$ & 20 & 49 \\
100-150 & & \\
151-890 & 15 & 37 \\
Dairy grazing surface (ha) & 26 & 63 \\
$\quad<100$ & & \\
100-560 & 14 & 34 \\
Calving system & 27 & 66 \\
$\quad$ All-year-round & & \\
At least over 2 different seasons & 5 & 12 \\
All-year-round housing & 5 & 12 \\
From weaned to bulling age & 4 & 10 \\
From bulling age to in-calf & & \\
Cows & 21 & 51 \\
Reports of helminth infections since 2010 & 20 & 49 \\
$\quad$ No & & \\
Yes & & \\
\hline
\end{tabular}


spectively. Tested heifers were, on average, 47 (38-58) DIM at sampling. Heifer median IM ODR was 0.64 (0.42-0.84). From October to December, correlation between heifer IM and BTM ODR was moderate $[\mathrm{r}=$ $0.54(0.17-0.77)]$.

\section{Multilevel Linear Regression Model for Heifer Exposure to Ostertagia ostertagi on Pasture}

Table 2 shows the results from the final multilevel linear regression model. We observed no significant differences in heifer IM ODR according to the seasons and the stage of lactation (i.e., DIM). Moreover, we found no significant interactions between both time and anthelmintic treatment and the final predictors of the model. Heifer IM ODR significantly decreased with increasing milk yield at sampling [Coefficient ( $\boldsymbol{\beta})(95 \%$ $\mathrm{CI})=-0.004(-0.006$ to -0.002$)]$ but significantly increased with higher SCC in milk $[\beta(95 \%$ CI $)=0.030$ (0.010-0.050)]. Compared with dairy crossbred, dairy purebred heifers had significantly higher IM ODR $[\beta$ $(95 \%$ CI $)=0.112(0.058-0.165)]$. Heifer IM ODR significantly decreased with an increasing number of dairy staff $[\beta(95 \%$ CI $)=-0.010(-0.020$ to $-0.002 \mathrm{E}-1)]$ and when young stock were sent in another farm for grazing $[\beta(95 \%$ CI $)=-0.096(-0.147$ to -0.044$)]$, but increased with increasing age at weaning on-farm $[\beta(95 \%$ $\mathrm{CI})=0.015(0.004-0.026)]$. Compared with heifers always turned out in the spring only, heifers turned out either in the spring/summer or in the spring/autumn had a significant decrease in IM ODR by -0.076 units $(95 \% \mathrm{CI}=-0.113$ to -0.039$)$. We noted a significant association between the contamination of pasture and heifer IM ODR. First, compared with heifers that did not co-graze with mature cows, heifers that co-grazed for more than $14 \mathrm{~d}$ with mature cows (i.e., either dry, milking, or both) had significantly higher IM ODR ( $\beta$ from 0.067 to 0.120). Second, heifers that went on pasture previously grazed by sheep during the first 2 grazing seasons had a significant increase in IM ODR ( $\beta$ from 0.073 to 0.174 ). Third, heifers that co-grazed with sheep at least during their third grazing season had a significant decrease in IM ODR by -0.196 units $(95 \% \mathrm{CI}=-0.387$ to -0.004$)$. Heifers that had higher minimum stocking rate during their first grazing season had significantly higher IM ODR $[\beta(95 \%$ CI $)=0.041$ (0.024-0.058)] and heifers that grazed more mowed pastures during their second grazing season had significantly lower IM ODR $[\beta(95 \%$ CI $)=-0.003(-0.006$ to $-0.003 \mathrm{E}-1)]$. After controlling for number of treatment application, heifers that were treated with long-acting anthelmintic treatments at turn-out or pour-on exclusively had significantly lower IM ODR ( $\beta$ from -0.108 to -0.219). Similarly, heifers that were treated with a combination of pour-on and injection during the grazing season and at housing had significantly lower IM ODR compared with nontreated heifers [ $\beta$ (95\% CI) $=-0.248(-0.400$ to -0.095$)]$. Final model residuals indicated a good overall fit; QQ plot indicated residuals were normally distributed and variance inflation factor of variables were $<10$.

\section{DISCUSSION}

This is the first longitudinal study using records of past anthelmintic treatments in heifers along with detailed grazing history and management practices to holistically investigate effects of these on heifer IM antibody levels against $O$. ostertagi. The study design and methods offered a reliable and valid approach to collect a wide range of data and address research questions that are particularly complex. First, it gave opportunities to engage with farmers, whose participation remained particularly high (95\%), which is of significant value in a longitudinal study (Goldstein et al., 2015). Second, the use of interviews allowed better understanding of local realities that are crucial for robustness of data analysis and interpretation. Despite the fact that we used a convenience sample of dairy farms that are members of QMMS, exposure to helminth and management history varied highly between heifers. Moreover, affiliation of farms to QMMS may have fostered active participation of farmers and collection of consistent and high-quality data on heifer management. The use of a stratified random sampling approach for the selection of heifers within farm ensured that all strata were represented in the sample and may have increased the precision of our results (Dohoo et al., 2009). Although possibly not generalizable to the entire population of English dairy farms, the underlying biological associations of risk factors reported in our study are likely to be valid for all-year-round dairy calving heifers in England. Our results suggest that grazing management factors not only have a significant effect on exposure to $O$. ostertagi irrespective of anthelmintic use, but also that their effect on exposure may vary depending on their timing in the grazing history.

After controlling for the effect of anthelmintic treatments, heifer IM ODR significantly increased in the case of an early start of the grazing season (spring). This result supports previous findings (Bennema et al., 2010) that cattle immunity against $O$. ostertagi develops slowly, only after long and repeated exposure to parasites on pasture (Klesius, 1988).

Our results also corroborated evidence suggesting that heifer co-grazing with adult cows significantly increases heifer exposure to $O$. ostertagi. In reality, our results suggest that such an association depends 
Table 2. Final multilevel linear regression model of association between heifer individual milk optical density ratio and demographic and management variables as fixed effects $\left(\mathrm{N}_{\text {heifers }}=1,454 \text { and } \mathrm{N}_{\text {farms }}=41\right)^{1}$

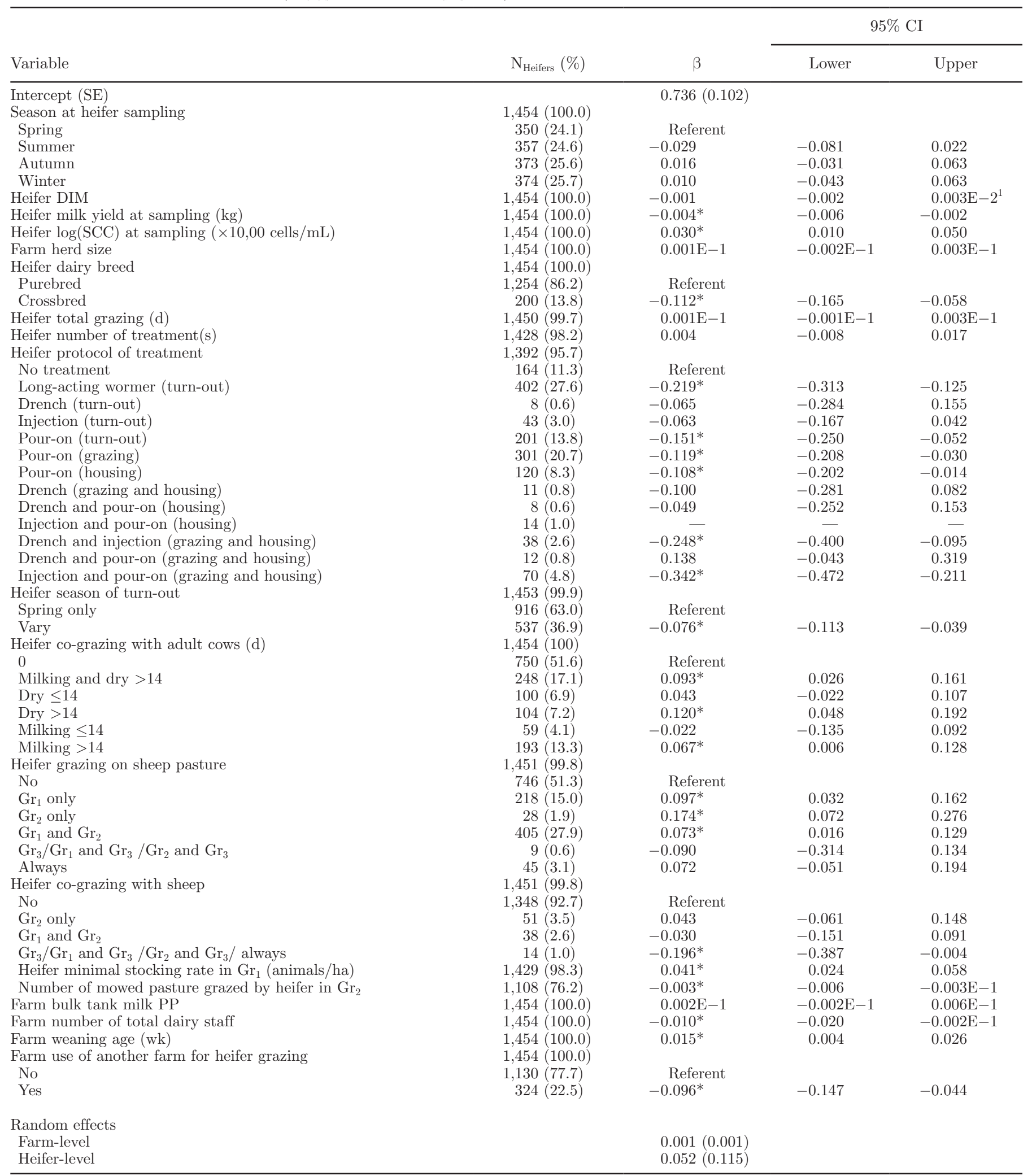

${ }^{1} \mathrm{E} x=10^{x} ; \mathrm{Gr}_{i}=$ grazing season $i ; \mathrm{PP}=$ marker for Fasciola hepatica.

$* P \leq 0.05$. 
on the timing in pregnancy when heifers co-graze with adult cows (i.e., before calving). Higher susceptibility of cattle to infections before calving has been reported in previous research and could be a reason for such an observation (Armour, 1980). By contrast, though this was poorly represented in our study, we observed that mixing heifers with sheep significantly decreased heifer exposure to $O$. ostertagi. Possible explanations for this could be that sheep can act as dead-end hosts for O. ostertagi (Waller, 2006; COWS, 2010) and that sheep behavior can influence ingestion of infective larvae by cattle (ADAS, 2011). Although our study suggests that sequential grazing of heifers with sheep may significantly increase heifer exposure to O. ostertagi, we believe this was due to some test cross-reactivity between the crude antigens used for the ELISA and antibodies against other nematodes common to both cattle and sheep (Roberts, 1942; Bennema et al., 2009).

To date, cattle risks of disease and production losses due to $O$. ostertagi have been mainly associated with a lack of host immunity against O. ostertagi (Fox, 1997). For this reason, best-practice guidelines often focus on young stock when providing advice for cattle helminth control in the UK (COWS, 2010). As these recommendations highlight, young stock exposure to O. ostertagi is positively associated with young stock stocking rate, something we observed in the current study but only for first-grazing heifers. Evidence suggests that naive animals are more likely to be infected when grazing highly stocked, contaminated pastures (Armour, 1980). Moreover, aligned with what is suggested in the COWS guidelines, higher frequencies of grass mowing in heifer pastures significantly decreased the level of heifer IM ODR, irrespective of time of turn-out and stocking rate. It is possible that the adverse microclimates or mechanical removal of $O$. ostertagi larvae following mowing caused the death of infective larvae on pasture (Armour, 1980; Waller, 2006). Moreover, mowed pastures are likely to be less intensively grazed or not grazed in the early season, reducing pasture larval contamination.

Most of the study farmers controlled helminth infections in their young stock, as shown by the difference of systematic treatments applied in young and adult cattle. Farmers integrated, to some extent, several best-practice recommendations included in COWS guidelines for cattle helminth control into their grazing management of heifers. For instance, heifers were on average turned out older than 6 mo of age; that is, when guidelines suggest that the risks of disease and production losses due to helminths are lower (COWS, 2010). Moreover, study farmers decreased the frequency of their anthelmintic use over time, possibly in line with COWS recommendations and the progressive build-up of host immunity against helminths (COWS, 2010). Farmers' use of anthelmintics remained high in our study, however. As evidence of this, most farms (95\%) treated heifers (88\%) against helminths before sampling and $37 \%$ used anthelmintics more than 4 times on heifers' first year of grazing, although rotating and mowing grass (COWS, 2010). It is likely that farmers' aversion to production loss, lack of complete understanding of what effect helminths have on production, and inability to adopt clean grazing influenced such practices (COWS, 2010; Taylor, 2010). In fact, 34 and $98 \%$ of first-grazing heifers co-grazed with cows and older young stock, respectively. Moreover, the convenience, safety, and ease of use of some anthelmintics can influence farmer's decision making on helminth control (Taylor, 2010; Wilson et al., 2015). As evidence of this, most farmers included in our study used pouron, long-lasting anthelmintics and ML, often formulated as pour-on (Taylor, 2010). Although concerns over helminth resistance to anthelmintics, especially ML, have been increasing in the UK (Coles, 2005; COWS, 2010), this finding also indicates that the issue of anthelmintic resistance might be of even more significant concern given prevalence of such practices (Charlier et al., 2015). In line with previous research (Wilson et al., 2015; O'Kane et al., 2017), our results suggest that farm labor and farmer conscientiousness (e.g., decision making based on the risk for heifers to be exposed or the build-up of cattle immunity) may influence farmers' decisions on cattle helminth control. Cattle helminth control cannot be considered separately from the rest of the farm-system management, as it can compete with other farm resources, such as number of staff, finance, and skills (Morley and Donald, 1980). The systematic approach adopted by conscientious farmers may also facilitate adoption of sustainable cattle helminth control. Moreover, conscientious farmers are more likely to take the time to search for information and to remain updated on the most efficient practices (O'Kane et al., 2017).

The accurate diagnosis of $O$. ostertagi infections is crucial to understand patterns of infection under field conditions. This depends on the tool used for the diagnosis and the interpretation of the results (Dohoo et al., 2009; Roeber et al., 2013). The high reproducibility of the Svanovir O. ostertagi ELISA kit observed in the current study supports previous findings of research done with adult cows (Sanchez et al., 2002c; Charlier et al., 2005b) and confirms that this kit is a very good candidate for conducting extensive longitudinal studies of $O$. ostertagi infections in cattle. Moreover, the only moderate correlation observed between heifer IM and BTM ODR corroborates earlier research (Sanchez et al., 2002b; Charlier et al., 2007), and suggests that 
IM should be the preferred choice when exploring $O$. ostertagi infection in young stock. Nevertheless, as we observed, it is important to note that several individual parameters, especially milk yield, SCC, and breed, are likely to influence ODR interpretations, possibly due to effects of dilution, test cross-reactivity, genetic traits, and physiology (Kloosterman et al., 1993; Sanchez et al., 2004; Liu et al., 2009). Therefore, these individual parameters should always be taken into account when interpreting ODR from heifer IM samples. It is also very important to mention that our overall understanding of mechanisms of host-parasite interactions and how immune responses are induced by $O$. ostertagi is still limited (Rinadi and Geldhof, 2012). For example, detection of milk antibodies does not allow us to differentiate between past and current infections and between different levels of infection severity. This might be a reason why no significant association could be observed between heifer IM ODR and time of grazing when the total time of heifer grazing was added up from birth to sampling; likewise, this confirms the importance of considering the interplay and variation of factors over the lifetime of cattle when exploring cattle exposure to helminths. Moreover, this also makes raw ODR a result that, on its own, is not informative (Wright et al., 1993) and the interpretation of factors associated with ODR often challenging (Roeber et al., 2013). Finally, some predictors included in the final model, such as age at weaning and size of the herd, may have acted as surrogate for other variables not captured in this study. As a consequence, further intervention studies are necessary in the field to test observed associations.

\section{CONCLUSIONS}

Our results suggest that length of grazing, stockingrate, mixed grazing with mature cows, and sequential grazing with sheep highly influence heifer exposure to $O$. ostertagi in England. Importantly, we observed that effects of such grazing-management practices depend on a heifer's susceptibility to parasite infections and, if managed with a particular care during the first year of heifer grazing and before calving, could help reducing the excessive use of anthelmintics by dairy farmers in the UK. Having examined various levers for action toward renewed grazing management practices that could be targeted by farmers, it is necessary to ensure the cost-effectiveness of these recommendations within the system of cattle farming, considering other cattle parasites and farm's socioeconomic dimensions that can influence cattle helminth control, such as financial resources and specific characteristics of the workforce, including availability of personnel and worker skills.

\section{ACKNOWLEDGMENTS}

The authors thank all the dairy farmers for their collaboration, as well as all the technicians from QMMS and Sum-It Computer Systems Ltd. for their help. Camille Bellet was supported by studentship from Agriculture and Horticulture Development Board Dairy (AHDB Dairy, Warwickshire, UK) and European Union Vice Chancellor Scholarship for Research Excellence, University of Nottingham.

\section{REFERENCES}

ADAS. 2011. Impact of grazing management on cattle and sheep parasites. ADAS report. Accessed Oct. 25, 2017. http://hccmpw.org .uk/index.php/tools/required/files/download?fID $=2336$.

AHDB. 2013. The structure of the GB dairy farming industry-What drives change? AHDB dairy report. Accessed Oct. 25, 2017. https://dairy.ahdb.org.uk/non_umbraco/download.aspx?media= 14129 .

AHDB. 2014. Fertility workshop. AHDB website. Accessed May 28, 2015. https://dairy.ahdb.org.uk/news/dairyleader-articles/ november-2014/fertility-workshop/\#.WSqv7ca1s2w.

AHDB. 2015. Managing replacement heifers for Better Returns AHDB Beef and Lamb report. Accessed Oct. 25, 2017. http:// beefandlamb.ahdb.org.uk/wp-content/uploads/2015/07/BRP -Managing-replacement-heifers-manual-11-030715.pdf.

Armour, J. 1980. The epidemiology of helminth disease in farm animals. Vet. Parasitol. 6:7-46.

Bellet, C., M. J. Green, M. Vickers, A. Forbes, E. Berry, and J. Kaler. 2016. Ostertagia spp., rumen fluke and liver fluke single- and polyinfections in cattle: An abattoir study of prevalence and production impacts in England and Wales. Prev. Vet. Med. 132:98-106.

Bennema, S., J. Vercruysse, E. Claerebout, T. Schnieder, C. Strube, E. Ducheyne, G. Hendrickx, and J. Charlier. 2009. The use of bulktank milk ELISAs to assess the spatial distribution of Fasciola hepatica, Ostertagia ostertagi and Dictyocaulus viviparus in dairy cattle in Flanders (Belgium). Vet. Parasitol. 165:51-57.

Bennema, S. C., J. Vercruysse, E. Morgan, K. Stafford, J. Hoglund, J. Demeler, G. von Samson-Himmelstjerna, and J. Charlier. 2010. Epidemiology and risk factors for exposure to gastrointestinal nematodes in dairy herds in northwestern Europe. Vet. Parasitol. 173:247-254.

Berk, Z., S. C. Bishop, A. B. Forbes, and I. Kyriazakisa. 2016. A simulation model to investigate interactions between first season grazing calves and Ostertagia ostertagi. Vet. Parasitol. 226:198-209.

Blanco-Penedo, I., J. Hoglund, N. Fall, and U. Emanuelson. 2012. Exposure to pasture borne nematodes affects individual milk yield in Swedish dairy herds. Vet. Parasitol. 188:93-98.

Charlier, J., P. Camuset, E. Claerebout, B. Courtay, and J. Vercruysse. 2007. A longitudinal survey of anti-Ostertagia ostertagi antibody levels in individual and bulk tank milk in two dairy herds in Normandy. Res. Vet. Sci. 83:194-197.

Charlier, J., E. Claerebout, E. De Muelenaere, and J. Vercruysse. 2005a. Associations between dairy herd management factors and bulk tank milk antibody levels against Ostertagia ostertagi. Vet. Parasitol. 133:91-100.

Charlier, J., L. Duchateau, E. Claerebout, and J. Vercruysse. 2005b. Assessment of the repeatability of a milk Ostertagia ostertagi ELISA and effects of sample preparation. Prev. Vet. Med. 68:277-288.

Charlier, J., M. Van der Voort, F. Kenyon, P. J. Skuce, and J. Vercruysse. 2014. Chasing helminths and their economic impact on farmed ruminants. Trends Parasitol. 30:361-367.

Charlier, J., F. V. Velde, M. van der Voort, J. Van Meensel, L. Lauwers, V. Cauberghe, J. Vercruysse, and E. Claerebout. 2015. ECONOHEALTH: Placing helminth infections of livestock in an economic and social context. Vet. Parasitol. 212:62-67. 
Coles, G. C. 2005. Anthelmintic resistance-Looking to the future: A UK perspective. Res. Vet. Sci. 78:99-108.

COWS. 2010. Integrated parasite control on cattle farms. COWS technical guide. Ed. 2014. Accessed Oct. 25, 2017. http://www .cattleparasites.org.uk/guidance/manual/COWS\%20Integrated $\% 20$ parasite $\% 20$ control $\% 20$ on $\% 20$ cattle\%20farms.pdf.

Dohoo, I., W. Martin, and H. Stryhn. 2009. Veterinary Epidemiologic Research. 2nd ed. VER Inc., Charlottetown, Canada.

Fox, M. T. 1997. Pathophysiology of infection with gastrointestinal nematodes in domestic ruminants: recent developments. Vet. Parasitol. 72:285-297., discussion 297-308.

Goldstein, H., P. Lynn, G. Muniz-Terrera, R. Hardy, C. O'Muicheartaigh, C. Skinner, and R. Lehtonen. 2015. Population sampling in longitudinal survey. Longit. Life Course Stud. 6:447-475.

Heasman, L., T. Potter, I. Nanjiani, D. Burden, and M. A. Taylor. 2012. Farmer practices and attitudes towards anthelmintic use in cattle in the United Kingdom. Westpoint Veterinary Group. Accessed Oct. 25, 2017. http://www.westpointfarmvets.co.uk/ wp-content/uploads/2015/01/Farmer-practices-and-attitudes -towards-anthelmintic-use-2012.pdf.

Hong, C., M. B. Lancaster, and J. F. Michel. 1981. Worm burdens of dairy heifers in England and Wales. Vet. Rec. 109:12-14.

Keus, A., A. Kloosterman, and R. Van den Brink. 1981. Detection of antibodies to Cooperia spp. and Ostertagia spp. in calves with the enzyme-linked immunosorbent assay (ELISA). Vet. Parasitol. 8:229-236.

Klesius, P. H. 1988. Immunity to Ostertagia ostertagi. Vet. Parasitol. $27: 159-167$.

Klesius, P. H. 1993. Regulation of immunity to Ostertagia ostertagi. Vet. Parasitol. 46:63-79.

Kloosterman, A., J. Verhoeff, H. W. Ploeger, and T. J. Lam. 1993. Antibodies against nematodes in serum, milk and bulk milk samples as possible estimators of infection in dairy cows. Vet. Parasitol. $47: 267-278$.

Lin, L. I. 1989. A concordance correlation coefficient to evaluate reproducibility. Biometrics 45:255-268.

Liu, G. L., J. Q. Wanga, D. P. Bua, J. B. Chenga, C. G. Zhanga, H. Y. Weia, L. Y. Zhoua, Z. F. Zhoua, H. Hua, and X. L. Donga. 2009. Factors affecting the transfer of immunoglobulin G1 into the milk of Holstein cows. Vet. J. 182:79-85.

McDonald, J. H. 2014. Handbook of Biological Statistics. 3rd ed. Sparky House Publishing, Baltimore, MD.

Merlin, A., A. Chauvin, A. Madouasse, S. Froger, N. Bareille, and C. Chartier. 2016. Explaining variability in first grazing season heifer growth combining individually measured parasitological and clinical indicators with exposure to gastrointestinal nematode infection based on grazing management practice. Vet. Parasitol. 225:61-69.

Morgan, E. R., B. C. Hosking, S. Burston, K. M. Carder, A. C. Hyslop, L. J. Pritchard, A. K. Whitmarsh, and G. C. Coles. 2012. A survey of helminth control practices on sheep farms in Great Britain and Ireland. Vet. J. 192:390-397.

Morley, F. H. W., and A. D. Donald. 1980. Farm management and systems of helminth control. Vet. Parasitol. 6:105-134.

O'Kane, H., E. Ferguson, J. Kaler, and L. E. Green. 2017. Associations between sheep farmer attitudes, beliefs, emotions and personality, and their barriers to uptake of best practice: The example of footrot. Prev. Vet. Med. 139:123-133.
Rasbash, J., F. Steele, W. J. Browne, and H. Goldstein. 2012. A user's guide to MLwiN version 2.26. Centre for Multilevel Modelling, University of Bristol, Bristol, UK.

Rinaldi, M., and P. Geldhof. 2012. Immunologically based control strategies for ostertagiosis in cattle: where do we stand? Parasite Immunol. 34:254-264.

Roberts, F. H. S. 1942. The host specificity of sheep and cattle helminths, with particular reference to the use of cattle in cleansing sheep pastures. Aust. Vet. J. 18:10-19.

Roeber, F., A. R. Jex, and R. B. Gasser. 2013. Advances in the diagnosis of key gastrointestinal nematode infections of livestock, with an emphasis on small ruminants. Biotechnol. Adv. 31:1135-1152.

Rushton, J., and M. Bruce. 2017. Using a One Health approach to assess the impact of parasitic disease in livestock: How does it add value? Parasitology 144:15-25.

Sanchez, J., I. Dohoo, A. Nodtvedt, G. Keefe, F. Markham, K. Leslie, L. DesCoteaux, and J. Campbell. 2002b. A longitudinal study of gastrointestinal parasites in Canadian dairy farms. The value of an indirect Ostertagia ostertagi ELISA as a monitoring tool. Vet. Parasitol. 107:209-226.

Sanchez, J., I. R. Dohoo, F. Markham, K. Leslie, and G. Conboy. 2002c. Evaluation of the repeatability of a crude adult indirect Ostertagia ostertagi ELISA and methods of expressing test results. Vet. Parasitol. 109:75-90.

Sanchez, J., F. Markham, I. Dohoo, J. Sheppard, G. Keefe, and K. Leslie. 2004. Milk antibodies against Ostertagia ostertagi: Relationships with milk IgG and production parameters in lactating dairy cattle. Vet. Parasitol. 120:319-330.

Sanchez, J., A. Nodtvedt, I. Dohoo, and L. DesCoteaux. 2002a. The effect of eprinomectin treatment at calving on reproduction parameters in adult dairy cows in Canada. Prev. Vet. Med. 56:165-177.

Sekiya, M., A. Zintl, and M. L. Doherty. 2013. Bulk milk ELISA and the diagnosis of parasite infections in dairy herds: a review. Ir. Vet. J. 66:14

Taylor, M. A. 2010. COWS. Sustainable Worm Control Strategies for Cattle. A Technical Manual for Veterinary Surgeons and Advisors. AHDB. Accessed Oct. 25, 2017. https://dairy.ahdb.org.uk/ non_umbraco/download.aspx?media $=7977$.

Vanderstichel, R., I. Dohoo, J. Sanchez, and G. Conboy. 2012. Effects of farm management practices and environmental factors on bulk tank milk antibodies against gastrointestinal nematodes in dairy farms across Canada. Prev. Vet. Med. 104:53-64.

Vercruysse, J., and E. Claerebout. 2001. Treatment vs non-treatment of helminth infections in cattle: defining the threshold. Vet. Parasitol. 98:195-214.

Waller, P. J. 2006. Sustainable nematode parasite control strategies for ruminant livestock by grazing management and biological control. Anim. Feed Sci. Technol. 126:277-289.

Wilson, L., A. P. Rhodes, and G. Dodunski. 2015. Parasite management extension-Challenging traditional practice through adoption of a systems approach. N. Z. Vet. J. 63:292-300.

Wright, P. F., E. Nilsson, E. M. A. Van Rooij, M. Lelenta, and M. H. Jeggo. 1993. Standardisation and validation of enzymelinked immunosorbent assay techniques for the detection of antibody in infectious disease diagnosis. Rev. Sci. Tech. 12:435-450. 